\title{
Integrated radon monitoring in Tatun Volcanic Areas of Northern Taiwan
}

\author{
Arvind Kumar ${ }^{1}$, Vivek Walia, ${ }^{1, *}$, Yi-Chun Sung ${ }^{1}$, Shih-Jung Lin ${ }^{1}$, Hasio-Fen Lee ${ }^{2}$, Cheng-Horng Lin ${ }^{2}$, \\ Ching-Chou $\mathrm{Fu}^{2}$, and Cheng-Hong $\mathrm{Chen}^{3}$ \\ ${ }^{1}$ National Center for Research on Earthquake Engineering, National Applied Research Laboratories, Taipei City, Taiwan \\ ${ }^{2}$ Institute of Earth Sciences, Academia Sinica, Taipei City, Taiwan \\ ${ }^{3}$ Department of Geosciences, National Taiwan University, Taipei City, Taiwan
}

\section{Article history:}

Received 13 January 2017

Revised 18 July 2017

Accepted 6 October 2017

Keywords:

Radon, Thoron, LR-115 films, Discriminative cup, Tatun volcanic areas

Citation:

Kumar, A., V. Walia, Y.-C. Sung, S.-J. Lin, H.-F. Lee, C.-H. Lin, C.-C. $\mathrm{Fu}$, and C.-H. Chen, 2018: Integrated radon monitoring in Tatun Volcanic Areas of Northern Taiwan. Terr. Atmos. Ocean. Sci., 29, 261-273, doi: 10.3319/TAO.2017.10.06.02

\begin{abstract}
Taiwan is highly active tectonically and intensively faulted resulting in occurrence of number of big earthquakes in the region. In the northern part of Taiwan Island, a group of volcanoes are distributed. These volcanoes are known as the Tatun volcano group (TVG). During the past decade, volcanological, seismological, and geochemical observations have shown that Tatun Volcano Group has potential for future eruptive activity. In the present study solid state nuclear track detectors (SSNTDs) technique has been used for the measurement of radon-thoron concentrations in soil gas for volcanic and seismic study in Taiwan. The semiautomatic track count using a Nikon digital camera coupled to a PC and employing software "SCION" has been checked and tested by comparing the results with manual counting. In order to study radon-thoron in volcanic areas, pre-calibrated radon-thoron discriminators with LR films has been installed in Hsiaoyoukeng (SYK), Dayoukeng (DYK), Bayen (BY), and Gungtzeping (GTP) of Tatun Volcanic area in a hole (about $50 \mathrm{~cm}$ depths) having different temperatures for a defined period (bi-weekly to monthly). Radon behaviour observed is different at above said sites. We have also monitor radon using SSNTDs along with active detectors (RAD 7) in Bayen (BY) area of Tatun for comparative study. The observations have shown potential precursory signals for some earthquakes that occurred during the observation period having an epicenter in and around the TVG. Our monitoring stations in TVG area are sensitive to the events within a distance of $60 \mathrm{~km}$.
\end{abstract}

\section{INTRODUCTION}

Since last few decades, scientific community has recognised that the variations of soil gas radon concentration as a useful tool for geodynamical monitoring in active fault zones (Singh et al. 1999; Walia et al. 2003, 2013; Planinić et al. 2004; Kumar et al. 2009) for surveillance in volcanic areas (Connor et al. 1996; Monnin and Seidel 1997; Segovia et al. 2003) and for tracing neotectonic faults (Burton et al. 2004). Rn-222 (radon hereafter) is a naturally occurring radioactive ( $3.8 \mathrm{~d}$ half-life) noble gas, produced in uranium bearing rocks as part of the U-238 decay series. Radon is generated within mineral grains by alpha decay from Ra226. Due to its recoil energy, radon can move in the solid material and migrate from the solid grain into the air or water

\footnotetext{
* Corresponding author

E-mail:vivekwalia@rediffmail.com
}

filled interstices of porous media (emanation).Within the air filled or water-filled pores, radon can migrate via diffusion towards lower concentration regions and/or via advection in response to a pressure gradient. Diffusive and advective transport processes in the pore space of porous materials enable radon to escape into the Earth's atmosphere and indoor environments (exhalation).

The Tatun Volcano Group (TVG) on the northern tip of the island of Taiwan covers an area of approximately $300 \mathrm{~km}^{2}$ (Fig. 1). It is only about $10 \mathrm{~km}$ north of the capital city of Taipei, which is characterized by andesitic flows that took place during and after the Early Pleistocene orogeny. From a tectonic point of view, it is located at the western end of the subduction system in the northern Taiwan area, where the Philippine Sea plate (PSP) is subducting northward beneath the Eurasian plate. Simultaneous subduction 
of the Philippine Sea plate is occurring under the Ryukyu arc located offshore (northeast of Taiwan).The group is composed of over 20 andesitic volcanic composites, cones, and domes (Chen and Wu 1971; Wang and Chen 1990), enclosed by NE-SW trending faults (Komori et al. 2013). A look at historical volcanic eruptions has suggested that volcanism has been extinct since the last major activity that occurred from 0.8 - 0.2 Ma BP (e.g., Juang 1993; Tsao 1994). However, recent studies offer suggestions that the potential for volcanic activity exists in the area: extensive hydrothermal activity is discharging a large amount of heat (e.g., Chen 1970); there are strongly acidic hot springs (pH approximately 1 to 3) (e.g., Liu et al. 2011; Ohsawa et al. 2013); magmatic contributions are found in fumarolic gases (e.g., Yang et al. 1999, 2003; Lee et al. 2005; Ohba et al. 2010); relatively young ejecta can be observed $(<<20 \mathrm{ka}$, Chen and Lin 2002; 6 ka, Belousov et al. 2010), and the presence of clustered seismicity and shallow pressure sources suggest fluid flows (Lin et al. 2005a; Konstantinou et al. 2007, 2009; Murase et al. 2014). Seismic (Lin et al. 2005b; Konstantinou et al.2007) and geochemical data (Yang et al. 1999, 2005a; Lee et al. 2005; Witt et al. 2008; Ohba et al. 2010) infer that a magma chamber may exist under northern Taiwan. In the recent study of both S-wave shadow and Pwave delay by Lin (2016) has shown substantial evidence for the presence of a deep magma reservoir. Data generated from GPS stations in TVG area have not demonstrated any clear deformation caused by volcanic activity (Lin et al. 2011; Murase et al. 2014). However, ground displacements at TVG reportedly (Yu et al. 1997; Shyu et al. 2005) controlled to first order by tectonics, which may be responsible for the long-term linear trends on the north and east components. In addition, seasonal displacements are attributed to atmospheric and hydrologic loading (Dong et al. 2002).

$\mathrm{Rn}-222$ (radon) is the major radioactive gas in the volcanic area. The study of radon concentration variations in volcanic areas has been considered as a useful tool to investigate the volcanic and seismic activity in one area (Cigolini et al. 2009; Moreno et al. 2009; Viveiros et al. 2009). Instruments for the measurements of radon and its decay products are based mostly on the detection of alpha particles. The radon sampling devices can be divided into active devices that require electric power to collect a sample and passive devices that do not require electric power (dry battery operated). SSNTDs are passive detectors, cheap and can be installed near the volcanic areas. They have some advantage over the active detectors, although the active detectors are more accurate and precise than passive detectors. In views of this in our earlier study (Kumar et al. 2013) cellulose nitrate alpha detector films (LR-115) were installed in discriminative cups at the selected site in Hsiaoyoukeng (SYK), Dayoukeng (DYK), Gungtzeping (GTP), and Byen (BY) of Tatun volcanic areas of northern Taiwan. Before installation of these films in the field, the LR-115 films in rodon-thoron discriminator has been calibrated and suitable site for integrated radon monitoring has been selected (Kumar et al. 2013). The low value for the thoron in TVG area has been observed which seems to be not useful for this study. The objective of this paper is monitor integrated radon concentration in TVG areas using SSNTDs to observe possible radon flux changes with and seismic and volcanic activities in the area. In addition to that radon behaviour

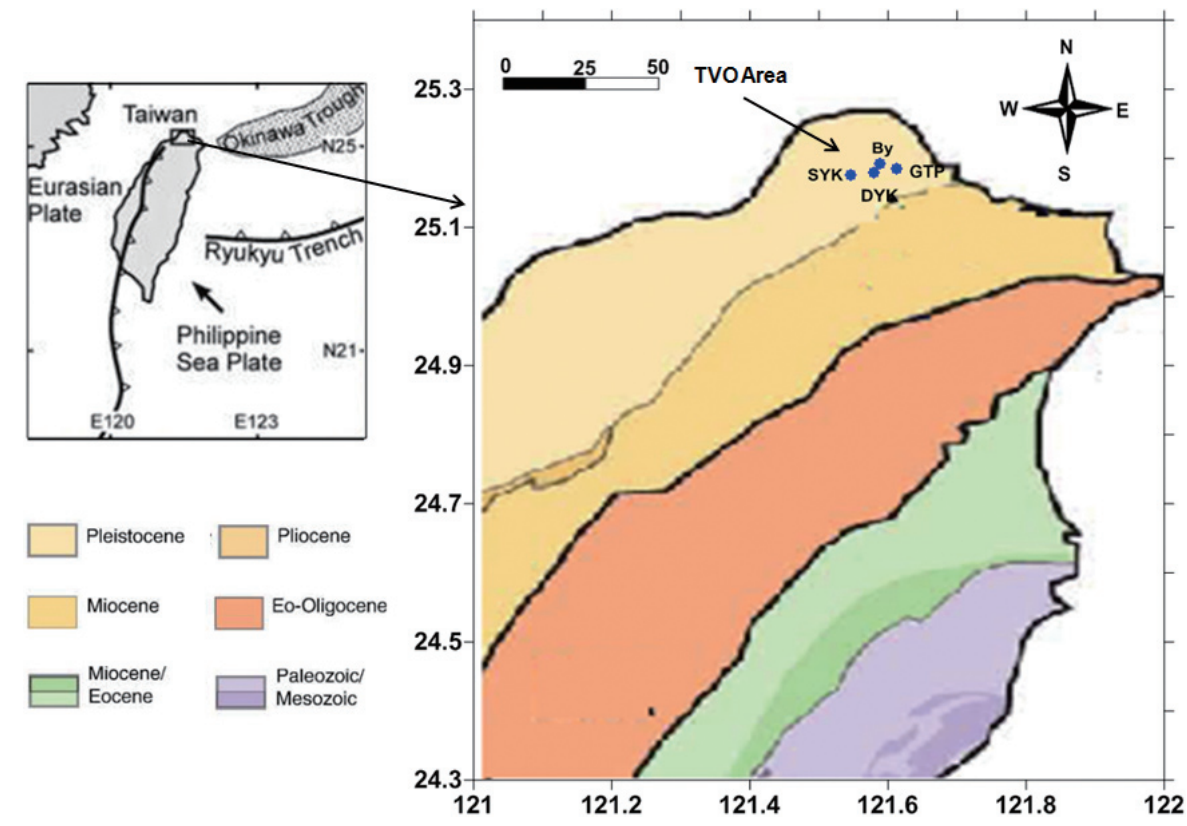

Fig. 1. Simplified geological map of Taiwan and geodynamic setting of the arc-continent collision, which shows the locations of monitoring stations in TVG area (modified from Mouthereau et al. 2009). 
observed at each station as well the result of radon concentration recorded with LR115 (passive detectors) and RAD7 (active detector) at By station for comparison study will also be presented.

\section{METHODOLOGY}

After the calibration of LR-115 films in radon-thoron discriminator and selecting the suitable site for radon monitoring in SYK, DYK, GTP, and BY of Tatun Volcanic areas (Fig. 1) as reported in the earlier study (Kumar et al. 2013). The integrated radon monitoring has been carried out by using LR-115 plastic detectors for volcanic and seismic study in sites mentioned above. For the present study, radon-thoron discriminators with LR films were installed in these sites having different temperatures in a hole (about $50 \mathrm{~cm}$ depths) for a defined period (bi-weekly to monthly). After retrieval and etching the films from the above sites the tracks were counted using semiautomatic methodology (Arias et al. 2005). It is a simple and reliable methodology with a semiautomatic track count using a Nikon digital camera coupled to a PC and employing software "SCION" freely available on the Internet (https://en.wikiversity.org/wiki/Scion Image). The computed tracks per $\mathrm{cm}^{2}$ in the films were converted to $\mathrm{kBq} \mathrm{m}^{-3}$ using the calibration factor calculated in the earlier study (Kumar et al. 2013). In order to study the radon variations with the metrological parameters and seismic activity in the study area, the respective data has been taken from Central Weather Bureau (http://www.cwb.gov.tw/eng/) and Tatun Volcanic Observatory, Taiwan. Taiwan is one of the most active seismic regions of the world with an average of about 20000 earthquakes occurring every year in or around Taiwan as reported by Central Weather Bureau of Taiwan (http://www.cwb.gov.tw). Therefore, it is essential to define selection criteria to identify threshold earthquakes for this study. From the literature, it has been found that the various criteria for selection of the earthquakes had been adopted by different studies (Fleischer 1981; Virk 1996; Martinelli and Dadomo 2017). However, from previous studies in Taiwan (Yang et al. 2005b; Fu et al. 2009; Walia et al. 2009, 2013; Kumar et al. 2015) the earthquake selection criteria has been defined as: earthquakes having local intensity $\geq$ 1 at the monitoring stations with epicentral distance $(\mathrm{R})<$ $100 \mathrm{~km}$ having $\mathrm{D} / \mathrm{R}$ ratio $\geq 1$ with focal depth $<40 \mathrm{~km}$. It is fitted well in different fault zones in Taiwan and used in the present study. In $\mathrm{D} / \mathrm{R}$ ratio, $\mathrm{D}$ is effective/strain radius ( $\mathrm{D}$ in $\mathrm{km}$ ) for earthquake preparation zone has been calculated by using Dobrovolsky et al. (1979) formula: $\mathrm{D}=10^{0.43 \mathrm{M}}$ and $\mathrm{R}$ is epicentral distance. Similarly, in order to identify possible threshold values of anomalous radon concentration, various statistical methods have been used by different authors in the past (Walia et al. 2005; Fu et al. 2009; Kumar et al. 2009). In the present context, statistical threshold values of gas anomalies are fixed at average $\left(\mathrm{x}^{-}\right)$plus one standard deviation $(\sigma)$. For defining the mean and standard deviation, the anomalously high and anomalously low value was neglected, which may cause unnecessary large variations and perturb the real anomalies.

\section{RESULTS}

Before using the semiautomatic track count using a Nikon digital camera coupled to a PC and employing software "SCION" it has been checked and tested by comparing the results with manual counting. To carry out this, radonthoron discriminators along with LR films were installed in different sites having different temperatures in a hole of about $50 \mathrm{~cm}$ depths. After a defined period (bi-weekly to monthly) of exposure, films were retrieved, etched and tracks were counted manually as well as semiautomatically by using the technique mentioned above. Tracks recorded for thoron was very low, so we were unable to find thoron concentration in these sites using this method. Table 1 shows the radon concentrations obtained by manual counting and semiautomatic counting. It is evident from the table that radon concentrations obtained by manual counting and semiautomatic counting are comparable and acceptable.

The distribution of background seismicity and all of the selected earthquake events, which satisfy our criteria in the TVG area during the observation period have shown in Fig. 2, along with a different symbolic representation of focal depth range. Data recorded in integrated soil gas radon monitoring using SSNTDs along with atmospheric temperature, pressure, rainfall and earthquake events at BY monitoring station for 2014 - 2016 times period has been shown in Fig. 3. No correlation of radon with metrological parameters has been observed in this monitoring station. Table 2 shows the correlations of radon anomalies observed in this station with the earthquake events occurred during this time period in the study area. Total seven radon anomalies have been recorded during this time period. Except for two anomalous radon value out of seven anomalous radon value have not correlated with the earthquake event during this time period. The first anomalous value in radon has been recorded from $2014 / 2 / 17$ to $2014 / 4 / 02$, which was followed by earthquake event of magnitude 4.0 on 2014/2/12. Whereas, one event of magnitude 4.2 was recorded prior to this anomalous value on 2014/1/21. The second anomalous value in radon has been recorded from $2014 / 08 / 22$ to $2014 / 10 / 15$, which was followed by earthquake events of magnitude 4.8 on 2014/11/20 . The third anomalous value in radon has been recorded from $2014 / 12 / 18$ to $2015 / 1 / 15$, which was followed by earthquake event of magnitude 4.7 on $2015 / 1 / 17$. The fourth anomalous value recorded from 2015/02/12 to 2015/2/26 has not been followed by any events. The fifth anomalous value in radon has been recorded from 2015/02/26 to 2015/3/13, which was followed by earthquake event of magnitude 4.1 on 2015/4/9. The sixth anomalous value recorded from 2015/12/02 to 
2015/12/21 has not been followed by any events. The seventh anomalous value in radon has been recorded from $2016 / 01 / 07$ to $2016 / 1 / 21$, which was followed by earthquake event of magnitude 4.0 on 2016/2/16. In this station, we have also used same soil gas source for radon monitoring using SSNTDs (passive detector) and RAD7 (active detector) for comparison. In the case of a passive method the interval is biweekly or more, but for active technique, the interval is shorter, i.e., 15 minutes. So for the comparison, 15 minutes data for active technique is reduced to biweekly or more. Figure 4 shows the comparison between the radon values observed in two different methods. It is evident from the figure that radon value trend observed by two different methods is almost same.

Figure 5 shows the data recorded in integrated soil gas radon monitoring using SSNTDs along with atmospheric temperature, pressure, rainfall and earthquake events at DYK monitoring station for 2014 - 2016 times period. No correlation of radon with metrological parameters has been observed from this monitoring station data. Table 3 shows the correlations of radon anomalies observed in this station with the earthquake events occurred during this time period in the study area. Total three radon anomalies have been recorded during this time period and have correlated with the earthquake event occurred in the study region. The first anomalous value in radon has been recorded from $2014 / 10 / 29$ to $2014 / 11 / 12$, which was followed by a seismic

Table 1. Radon concentrations calculated after weekly or biweekly exposure of SSNTDS films at TVG area by manual counting as well as semiautomatic counting.

\begin{tabular}{|c|c|c|c|c|}
\hline \multicolumn{5}{|c|}{ GTP } \\
\hline \multicolumn{2}{|c|}{ Temperature $\left({ }^{\circ} \mathbf{C}\right)$} & \multirow{2}{*}{$\begin{array}{c}\text { Exposure } \\
\text { Time }\end{array}$} & \multicolumn{2}{|c|}{$\begin{array}{c}\text { Radon Concentration } \\
\left(\mathbf{k B q ~}^{-3}\right)\end{array}$} \\
\hline $\begin{array}{c}\text { During } \\
\text { Installation }\end{array}$ & $\begin{array}{c}\text { During } \\
\text { Retrieval }\end{array}$ & & $\begin{array}{c}\text { Manual } \\
\text { counting }\end{array}$ & $\begin{array}{c}\text { Semiautomatic } \\
\text { counting }\end{array}$ \\
\hline 56 & 60 & 14 & 40.2 & 36.0 \\
\hline 57 & 60 & 20 & 8.8 & 7.0 \\
\hline 55 & 59 & 22 & 2.9 & 3.2 \\
\hline \multicolumn{5}{|c|}{ SYK } \\
\hline 22.7 & 23 & 22 & 13.18 & 12.95 \\
\hline 25 & 26 & 26 & 10.28 & 9.28 \\
\hline 22 & 24 & 20 & 6.04 & 4.72 \\
\hline \multicolumn{5}{|c|}{ DYK } \\
\hline 63 & 65 & 25 & 2.54 & 2.13 \\
\hline 60 & 63 & 23 & 1.58 & 0.97 \\
\hline 46.8 & 39.1 & 14 & 1.21 & 0.69 \\
\hline
\end{tabular}

event of magnitude 4.8 on 2014/11/20. The second anomalous value in radon has been recorded from 2014/12/03 to $2015 / 1 / 15$, which was followed by two seismic events of magnitude 4.0 and 4.7 on 2014/12/21 and 2015/1/17, respectively. The third anomalous value in radon has been recorded from 2015/12/21 to 2016/2/19, which was followed by a seismic event of magnitude 4 on 2016/2/16.

Recorded integrated soil gas radon data at GTP monitoring station using SSNTDs along with atmospheric temperature, pressure, rainfall and seismic events for 2014 2016 times period has been shown in Fig. 6. This station has also not shown any correlation of radon with metrological parameters during this time period. Table 4 shows the correlations of radon anomalies observed in this station with the earthquake events occurred during this time period in the study area. Total five radon anomalies have been recorded during this time period. Except for one anomalous radon value out of five anomalous radon value have not correlated with the earthquake event during this time period.

The first anomalous value in radon has been recorded from 2014/03/21 to 2014/4/2. One event of magnitude 3.3 is recorded prior to this anomalous value on $2014 / 3 / 10$. The second anomalous value in radon has been recorded from 2014/07/11 to 2014/08/08. Before and after of this anomaly no events were recorded. The third anomalous value in radon has been recorded from 2014/09/18 to 2014/12/18, which was followed by two earthquake events of magnitude 4.8 and

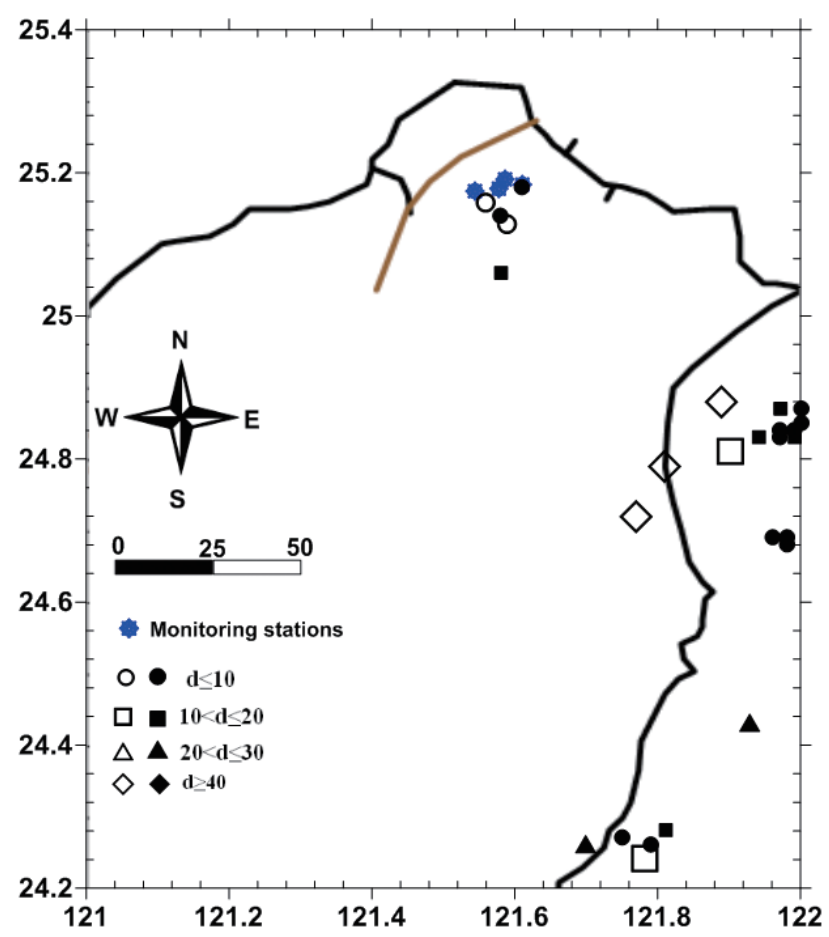

Fig. 2. Map showing the distribution of background seismicity and all of the selected earthquake events which satisfied our selection criteria recorded in TVG area during the study period. Seismic events are given by different symbolic representation of focal depth range. 


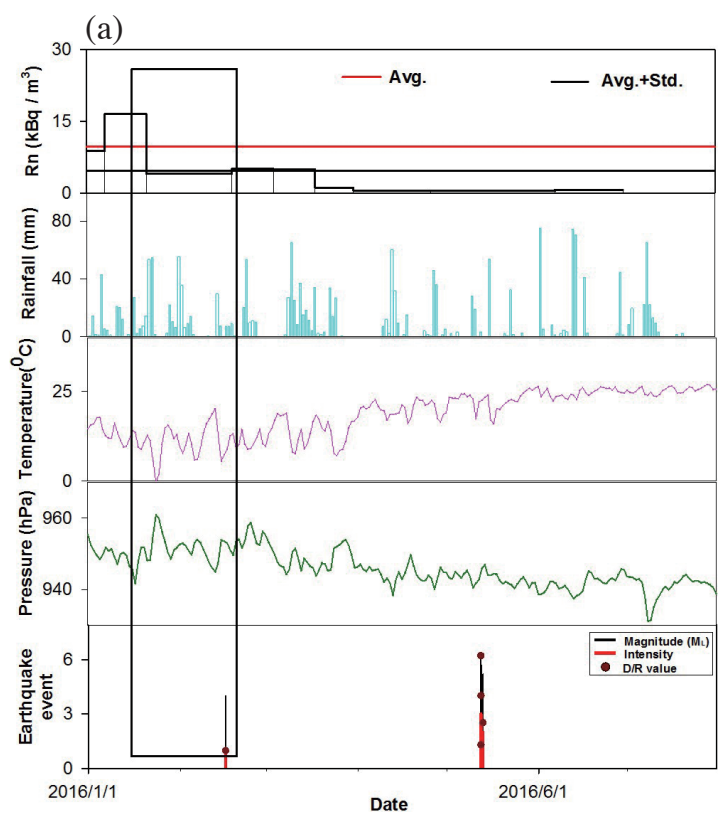

(c)

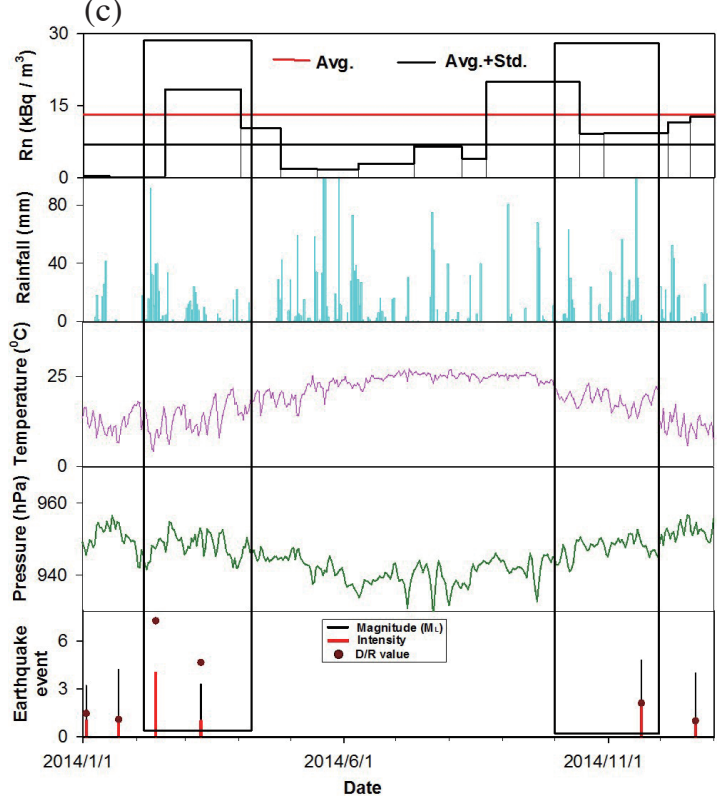

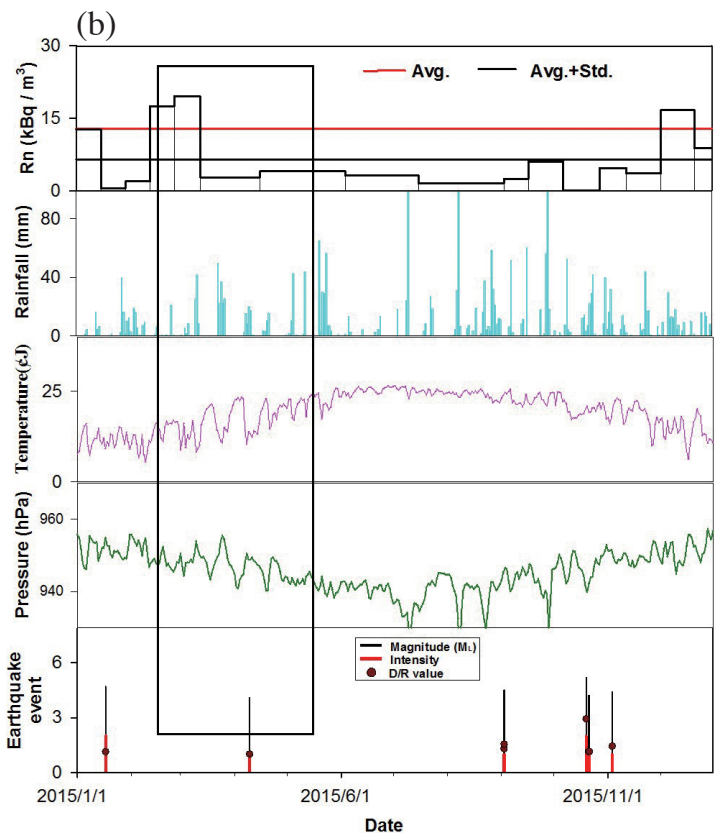
Fig. 3. Plots of recorded integrated soil gas radon using SSNTDs along with atmospheric temperature, pressure, rainfall, and earthquake events
recorded by central weather bureau at BY from the period of $2014-2016$. Black rectangle shows the earthquake events recorded after and before the anomalous radon values.

Table 2. Shows the time of radon anomalies observed, earthquake events recorded after and before the anomalous radon value and earthquake events parameter, i.e., magnitude, depth, intensity, surface distance, direct distance, and D/R in BY station with the earthquake events occurred in the study area.

\begin{tabular}{|c|c|c|c|c|c|c|c|}
\hline Anomaly time & EQ time & $\mathbf{M}_{\mathbf{L}}$ & Depth $(\mathbf{k m})$ & Intensity & Surface distance $(\mathbf{k m})$ & Direct distance (km) & $\mathbf{D} / \mathbf{R}$ \\
\hline \multirow[t]{2}{*}{$2014 / 2 / 17-2014 / 4 / 02$} & 2014/1/21 13:53:00 & 4.2 & 3.9 & 1 & 59 & 59 & 1.08 \\
\hline & 2014/2/12 0:31:00 & 4 & 6.3 & 4 & 4 & 7 & 7.26 \\
\hline $2014 / 08 / 22-2014 / 10 / 15$ & 2014/11/20 1:46:00 & 4.8 & 9 & 2 & 54 & 55 & 2.11 \\
\hline $2014 / 12 / 18-2015 / 1 / 15$ & 2015/1/17 3:12:00 & 4.7 & 22.4 & 2 & 89 & 92 & 1.14 \\
\hline \multicolumn{8}{|l|}{$2015 / 02 / 12-2015 / 2 / 26$} \\
\hline $2015 / 02 / 26-2015 / 3 / 13$ & 2015/4/9 13:48:00 & 4.1 & 13.4 & 1 & 56 & 58 & 1.00 \\
\hline \multicolumn{8}{|l|}{$2015 / 12 / 02-2015 / 12 / 21$} \\
\hline $2016 / 01 / 07-2016 / 1 / 21$ & $2016 / 2 / 167: 35: 00$ & 4 & 11 & 1 & 52 & 54 & 0.98 \\
\hline
\end{tabular}


Fig. 4. Comparison plot between the radon value observed by RAD7 (active detector) and SSNTDs (passive detector) from the period of 2014/01/01 to 2015/01/01.

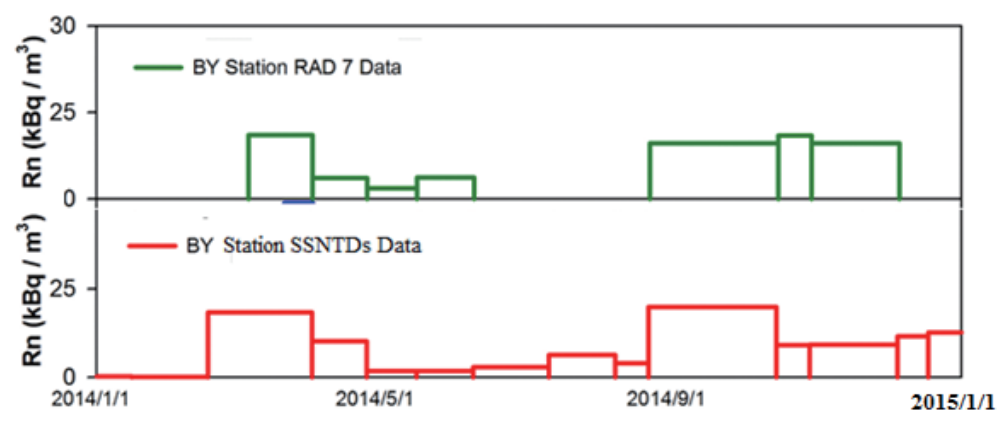

(a)

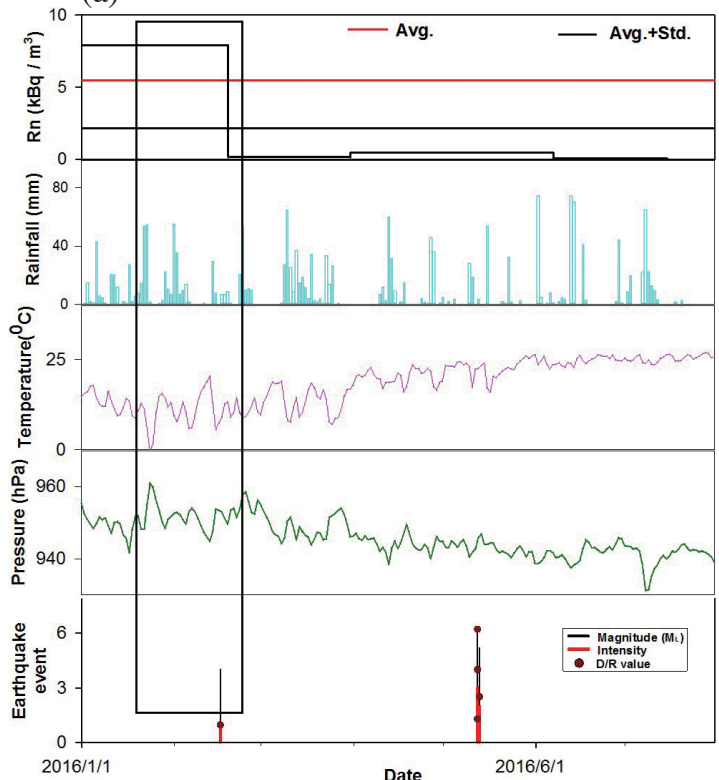

(c)

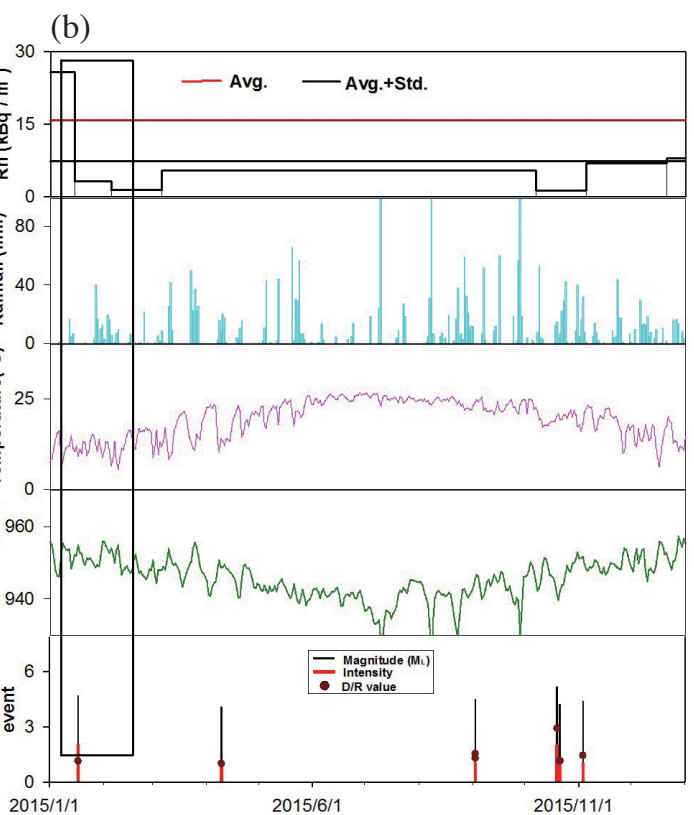

Date

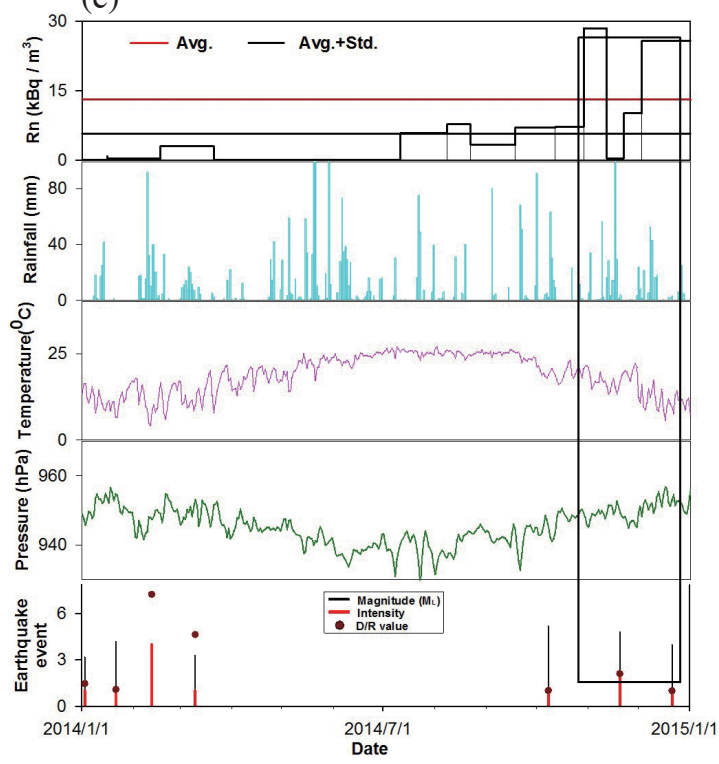

Fig. 5. Plots of recorded integrated soil gas radon using SSNTDs along with atmospheric temperature, pressure, rainfall, and earthquake events recorded by central weather bureau at DYK from the period of 2014 - 2016. Black rectangle shows the earthquake events recorded after and before the anomalous radon values. 
Table 3. Shows the time of radon anomalies observed, earthquake events recorded after and before the anomalous radon value and earthquake events parameter, i.e., magnitude, depth, intensity, surface distance, direct distance, and D/R in DYK station with the earthquake events occurred in the study area.

\begin{tabular}{|c|c|c|c|c|c|c|c|}
\hline Anomaly time & EQ time & $\mathbf{M}_{\mathbf{L}}$ & Depth $(\mathbf{k m})$ & Intensity & Surface distance $(\mathbf{k m})$ & Direct distance $(\mathbf{k m})$ & $\mathbf{D} / \mathbf{R}$ \\
\hline \multirow[t]{2}{*}{$2014 / 10 / 29-2014 / 11 / 12$} & 2014/11/20 1:46:00 & 4.8 & 9 & 2 & 54 & 55 & 2.11 \\
\hline & 2014/12/21 9:12:00 & 4 & 10.3 & 1 & 52 & 53 & 1.00 \\
\hline $2014 / 12 / 03-2015 / 1 / 15$ & 2015/1/17 3:12:00 & 4.7 & 22.4 & 2 & 89 & 92 & 1.14 \\
\hline $2015 / 12 / 21-2016 / 2 / 19$ & $2016 / 2 / 16$ 7:35:00 & 4 & 11 & 1 & 52 & 54 & 0.98 \\
\hline
\end{tabular}
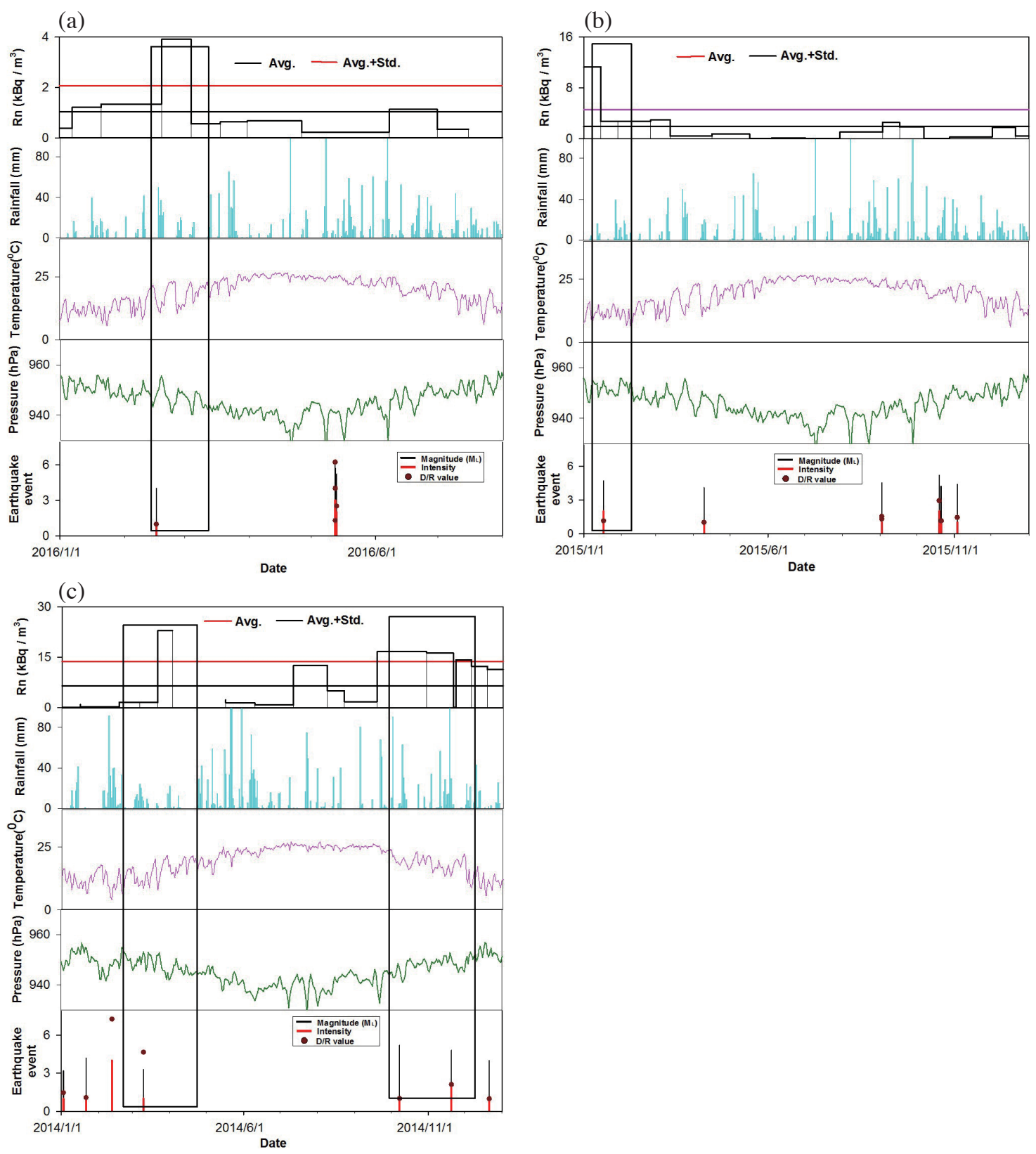

Fig. 6. Plots of recorded integrated soil gas radon using SSNTDs along with atmospheric temperature, pressure, rainfall, and earthquake events recorded by central weather bureau at GTP from the period of 2014 - 2016. Black rectangle shows the earthquake events recorded after and before the anomalous radon values. 
Table 4. Shows the time of radon anomalies observed, earthquake events recorded after and before the anomalous radon value and earthquake events parameter, i.e., magnitude, depth, intensity, surface distance, direct distance, and D/R in GTP station with the earthquake events occurred in the study area.

\begin{tabular}{cccccccc}
\hline Anomaly time & EQ time & $\mathbf{M}_{\mathbf{L}}$ & Depth $(\mathbf{k m})$ & Intensity & Surface distance $(\mathbf{k m})$ & Direct distance $(\mathbf{k m})$ & D/R \\
\hline 2014/03/21 - 2014/4/2 & $2014 / 3 / 103: 47: 00$ & 3.3 & 4.7 & 1 & 3 & 6 & 4.65 \\
2014/07/11 - 2014/08/08 & & & & & & & \\
2014/09/18 - 2014/12/18 & $2014 / 11 / 20 ~ 1: 46: 00$ & 4.8 & 9 & 2 & 54 & 55 & 2.11 \\
& $2014 / 12 / 219: 12: 00$ & 4 & 10.3 & 1 & 52 & 53 & 1.00 \\
& $2014 / 12 / 219: 12: 00$ & 4 & 10.3 & 1 & 52 & 53 & 1.00 \\
$2014 / 12 / 18-2015 / 1 / 15$ & $2015 / 1 / 173: 12: 00$ & 4.7 & 22.4 & 2 & 89 & 92 & 1.14 \\
$2016 / 02 / 19-2016 / 3 / 4$ & $2016 / 2 / 167: 35: 00$ & 4 & 11 & 1 & 52 & 54 & 0.98 \\
\hline
\end{tabular}

4.0 on $2014 / 11 / 20$ and $2014 / 12 / 21$, respectively. The fourth anomalous value recorded from 2014/12/18 to 2015/1/15, which was followed by earthquake event of magnitude 4.7 on 2015/1/17. The fifth anomalous value in radon has been recorded from 2016/02/19 to 2016/3/4, which was followed by earthquake event of magnitude 4.0 on 2016/2/16.

Integrated soil gas radon monitoring data recorded using SSNTDs along with atmospheric temperature, pressure, rainfall, and earthquake events at SYK monitoring station for 2014 - 2016 times period has been shown in Fig. 7. This station has also shown no correlation of radon with metrological parameters. Table 5 shows the correlations of radon anomalies observed in this station with the earthquake events occurred during this time period in the study area. Total three radon anomalies have been recorded during this time period and have correlated with the earthquake event occurred in the study region. The first anomalous value in radon has been recorded from 2014/11/22 to 2014/12/5, which was followed by earthquake event of magnitude 4.0 on $2014 / 12 / 21$. Where as one event of magnitude 4 prior to this anomalous value has been recorded on 2014/12/21. The second anomalous value in radon has been recorded from $2015 / 03 / 13$ to $2015 / 4 / 2$, which was followed by two earthquake event of magnitude 4.1 on 2015/4/9. The third anomalous value in radon has been recorded from 2016/02/19 to $2016 / 3 / 4$, which was followed by earthquake event of magnitude 4.0 on 2016/2/16.

\section{DISCUSSIONS}

Semiautomatic track count using a Nikon digital camera coupled to a PC and employing software "SCION" semiautomatic method for track counting is helpful to save time and get rid of counting the etched tracks under an optic microscope manually which is a tedious and time-consuming procedure.

The observations have shown potential precursory signals for some earthquakes that occurred during the observation period. Anomalous radon value has been observed for the events of magnitude 4 and 4.7 , which were occurred on 2016/2/16 and 2015/1/17 respectively in all the monitoring stations. For the event of magnitude 4.8 which were recorded on 2014/11/20 have shown anomalous value in three stations, i.e., at BY, DYK, and GTP. In the present study, most of the seismic events related with radon anomalies are of magnitude $\geq 4$. Only one earthquake of magnitude 3.3 with a shallow focal depth of $4.7 \mathrm{~km}$ and epicentral distance less than $5 \mathrm{~km}$ (see Tables 2 - 5) has been recorded. In TVG area, clustered micro-earthquakes with some typical volcanic characteristics have been reported (Lin et al. 2005a, b; Konstantinou et al. 2007). In total more than five thousand microearthquakes with a local magnitude $<3$ have occurred in the area from 2003 - 2015. Most of these micro-earthquakes are classified as volcano-tectonic earthquakes, or often called A-type volcanic earthquakes, which have a double-couple source and thus both P- and S-waves can be identified (Lin et al. 2005a). Moreover, a few of the earthquakes detected at the TVG are recognized as typical volcanic earthquakes such as short-duration monochromatic events, long-duration spasmodic bursts and a phreatic eruption (Lin et al. 2005a, b; Konstantinou et al. 2007; Lin 2016).

In all the precursory studies, authors aimed to find anomalies prior to seismic events. However, in some cases, post-seismic anomalies have also been found by various studies (Hartmann and Levy 2005). So in our case, we did find some correlated anomalies to post-seismic events. Four monitoring sites in the present study are geographical close to each other but they have different characteristics in anomalous signals detecting. This may be due to the different reasons, e.g., temperature, radon flux, etc.

Most of the earthquakes correlated with anomalous radon value are within $60 \mathrm{~km}$ from the monitoring stations (Fig. 8). So from this study, we can also conclude that our monitoring stations in TVG area are sensitive to the events within the distance of $60 \mathrm{~km}$. Continue longterm monitoring in these stations is required to test and verify this hypothesis in future.

Table 6 shows the yearly average value and standard 
(a)

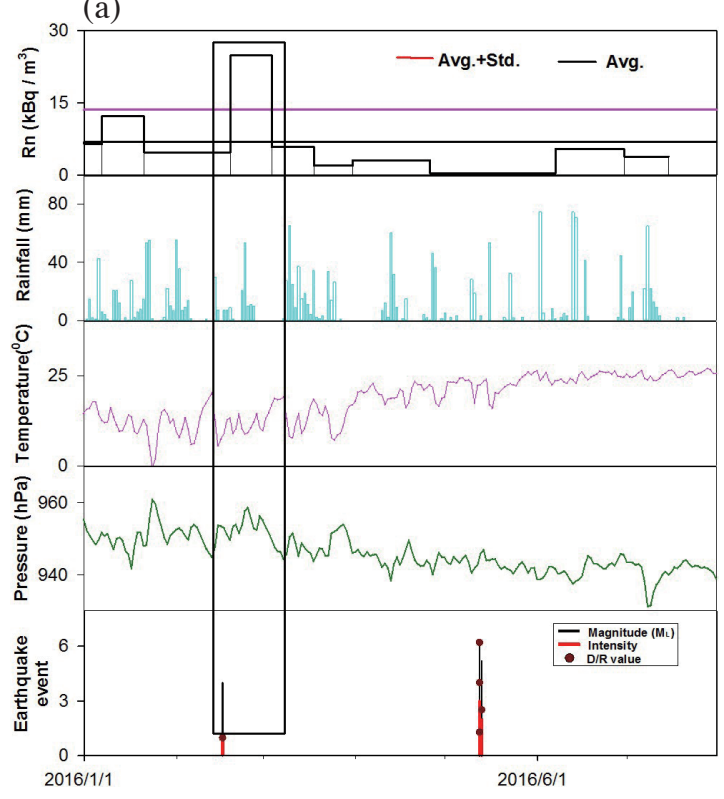

(c)

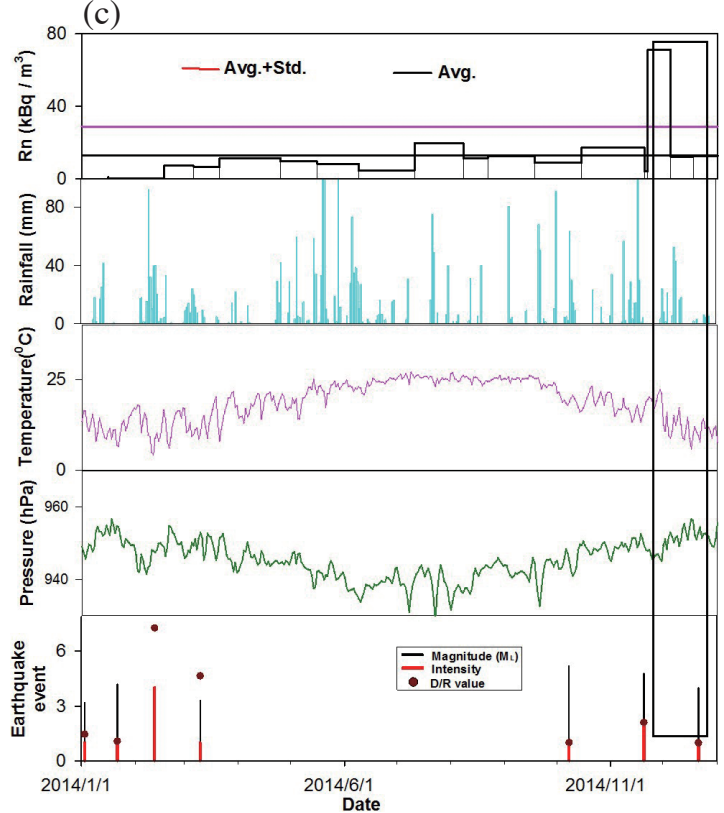

(b)

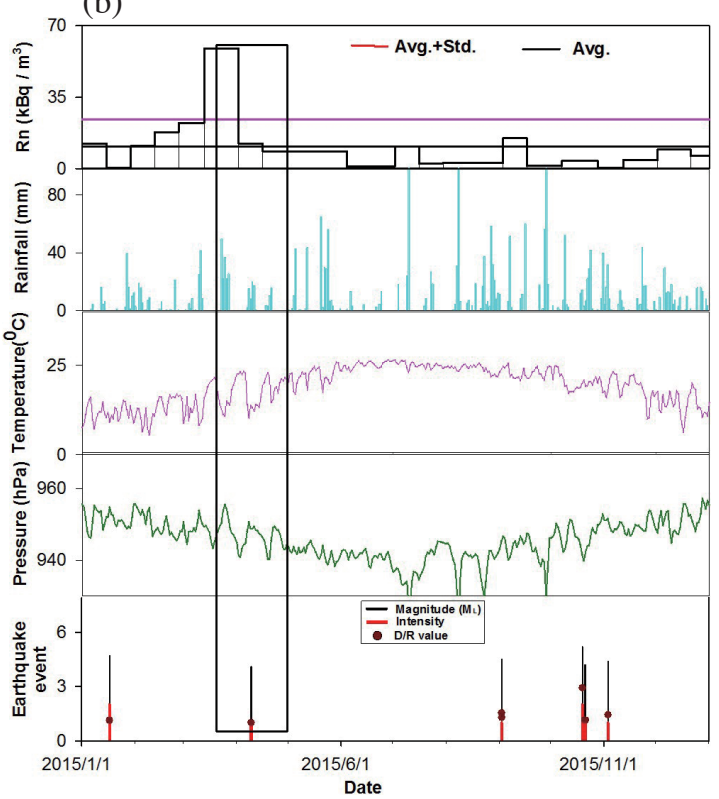

Fig. 7. Plots of recorded integrated soil gas radon using SSNTDs along with atmospheric temperature, pressure, rainfall, and earthquake events recorded by central weather bureau at SYK from the period of 2014 - 2016. Black rectangle shows the earthquake events recorded after and before the anomalous radon values.

Table 5. Shows the time of radon anomalies observed, earthquake events recorded after and before the anomalous radon value and earthquake events parameter, i.e., magnitude, depth, intensity, surface distance, direct distance, and D/R in SYK station with the earthquake events occurred in the study area.

\begin{tabular}{cccccccc}
\hline Anomaly time & EQ time & $\mathbf{M}_{\mathbf{L}}$ & Depth $(\mathbf{k m})$ & Intensity & Surface distance $(\mathbf{k m})$ & Direct distance $(\mathbf{k m})$ & $\mathbf{D} / \mathbf{R}$ \\
\hline $2014 / 11 / 22-2014 / 12 / 5$ & $2014 / 12 / 21$ 9:12:00 & 4 & 10.3 & 1 & 52 & 53 & 1.00 \\
& $2015 / 1 / 173: 12: 00$ & 4.7 & 22.4 & 2 & 89 & 52 & 1.14 \\
$2015 / 03 / 13-2015 / 4 / 2$ & $2015 / 4 / 913: 48: 00$ & 4.1 & 13.4 & 1 & 56 & 58 & 1.00 \\
$2016 / 02 / 19-2016 / 3 / 4$ & $2016 / 2 / 167: 35: 00$ & 4 & 11 & 1 & 52 & 54 & 0.98 \\
\hline
\end{tabular}




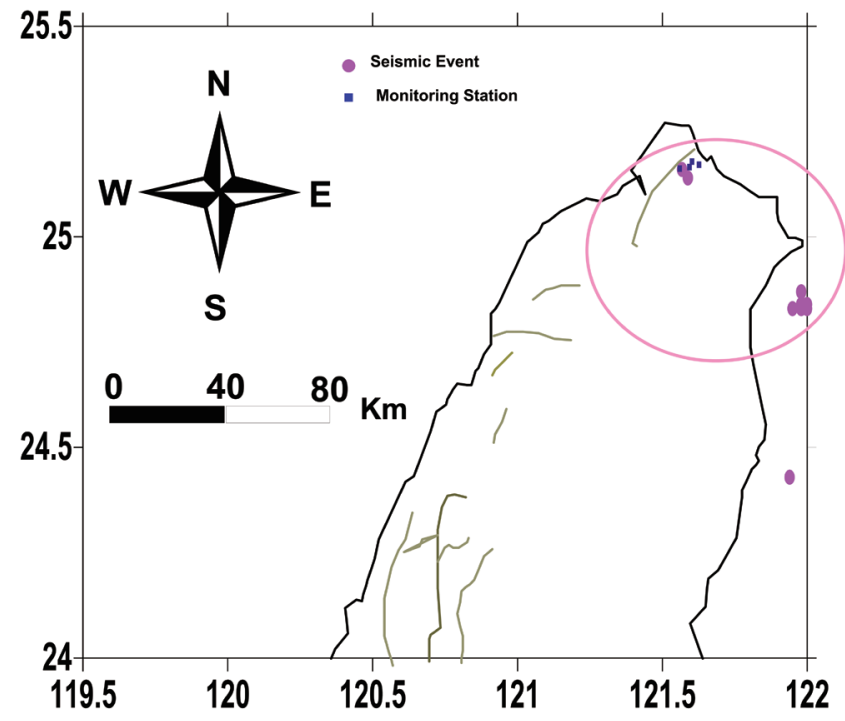

Fig. 8. Map showing the locations of monitoring stations and events correlated with the anomalous value of radon in TVG area, whereas, the circle represents the sensitive zone for the monitoring stations.

Table 6. Average radon and standard deviation value observed in TVG area monitoring stations, i.e., GTP, SYK, DYK, and BY from the period of $2014-2016$.

\begin{tabular}{c|ccc}
\hline Monitoring Station & $\mathbf{2 0 1 4}$ & $\mathbf{2 0 1 5}$ & $\mathbf{2 0 1 6}$ \\
\hline \multicolumn{4}{c}{ Average Radon $\left(\mathbf{k B q ~ m}^{-3}\right)$} \\
GTP & 6.48 & 1.89 & 1.05 \\
SYK & 12.88 & 10.92 & 6.85 \\
DYK & 5.73 & 7.34 & 2.15 \\
BY & 6.88 & 6.49 & 4.71 \\
\hline \multicolumn{4}{c}{ Standard Deviation } \\
GTP & 7.3 & 2.7 & 1.0 \\
SYK & 16.0 & 13.2 & 6.7 \\
DYK & 7.4 & 8.5 & 3.3 \\
BY & 6.3 & 6.4 & 5.0 \\
\hline
\end{tabular}

deviation recorded in each station in TVG areas from 2014 - 2016. Annual average radon value is decreasing in all the stations from 2014 - 2016. The maximum annual average value is recorded at SYK $\left(12.88 \mathrm{kBq} \mathrm{m}^{-3}\right)$ in 2014 whereas minimum annual average value is recorded at GTP $\left(1.05 \mathrm{kBq} \mathrm{m}^{-3}\right)$ in 2016 . Various authors have noticed that radon value changes with time (i.e., seasonal variations, annual variation, etc.) due to many factors. Also, it can be seen from the recorded data that radon behaviour is different at different sites. This may be attributable to the difference in radon flux and temperature range (may be due to the presence of fumaroles and vents) in the respective sites (Kumar et al. 2013). In other words, radon emanation is effected by temperature. In general radon shows a positive correlation with temperature, i.e., the value of radon concentration increases as temperature increases and decreases with decrease in temperature. It is considered that in TVG area hydrothermal fluid may be supplied from the magma chamber to the deep hydrothermal reservoir at a depth of 2 $\mathrm{km}$ (Murase et al. 2014). However, some crustal deformation associated with this kind of fluid input event can not be detected by using the present radon study.

\section{CONCLUSIONS}

The efficiency of semiautomatic track count method (Nikon digital camera coupled to a PC and employing software "SCION") has been checked and tested in the present study. Also, the integrated soil gas radon data using SSNTDs (in boreholes of about $50 \mathrm{~cm}$ ) at four different places in TVG has been generated for seismic and volcanic study. The recorded data have shown that radon behaviour is different at different sites. No correlation of radon with meteorological parameters has been observed in the monitoring stations of TVG area. The observed data have also shown potential precursory signals for some earthquakes that occurred during the observation period. Our monitoring stations in TVG area are sensitive to the events within a distance of $60 \mathrm{~km}$. Continuous long-term monitoring in these stations is required to test and verify this hypothesis in future.

Acknowledgements The authors are thankful to Ministry of Science and Technology Taiwan for supporting this work financially under the projects VW/MOST 105-2116-M492-003 and 105-2811-M-492-004.

\section{REFERENCES}

Arias, H., D. Palacios, L. Sajó-Bohus, and T. Viloria, 2005: Alternative procedure for LR 115 chemical etching and alpha tracks counting. Radiat. Meas., 40, 357-362, doi: 10.1016/j.radmeas.2005.05.020. [Link]

Belousov, A., M. Belousova, C.-H. Chen, and G. F. Zellmer, 2010: Deposits, character and timing of recent eruptions and gravitational collapses in Tatun Volcanic Group, Northern Taiwan: Hazard-related issues. J. Volcanol. Geotherm. Res., 191, 205-221, doi: 10.1016/j. jvolgeores.2010.02.001. [Link]

Burton, M., M. Neri, and D. Condarelli, 2004: High spatial resolution radon measurements reveal hidden active faults on Mt. Etna. Geophys. Res. Lett., 31, L07618, doi: 10.1029/2003gl019181. [Link]

Chen, C.-H., 1970: Geology and geothermal power potential of the Tatun volcanic region. Geothermics, 2, 11341143, doi: 10.1016/0375-6505(70)90425-6. [Link]

Chen, C.-H. and S.-B. Lin, 2002: Eruptions younger than $20 \mathrm{ka}$ of the Tatun Volcano Group as viewed from the sediments of the Sungshan Formation in Taipei Basin. 
West. Pac. Earth Sci., 2, 193-206.

Chen, C.-H. and Y.-J. Wu, 1971: Volcanic geology of the Tatun geothermal area, northern Taiwan. Proc. Geol. Soc. China, 14, 5-20.

Cigolini, C., P. Poggi, M. Ripepe, M. Laiolo, C. Ciamberlini, D. Delle Donne, G. Ulivieri, D. Coppola, G. Lacanna, E. Marchetti, D. Piscopo, and R. Genco, 2009: Radon surveys and real-time monitoring at Stromboli volcano: Influence of soil temperature, atmospheric pressure and tidal forces on 222Rn degassing. J. Volcanol. Geotherm. Res., 184, 381-388, doi: 10.1016/j. jvolgeores.2009.04.019. [Link]

Connor, C., B. Hill, P. LaFemina, M. Navarro, and M. Conway, 1996: Soil222Rn pulse during the initial phase of the June-August 1995 eruption of Cerro Negro, Nicaragua. J. Volcanol. Geotherm. Res., 73, 119-127, doi: 10.1016/0377-0273(96)00020-0. [Link]

Dobrovolsky, I. P., S. I. Zubkov, and V. I. Miachkin, 1979: Estimation of the size of earthquake preparation zones. Pure Appl. Geophys., 117, 1025-1044, doi: 10.1007/ bf00876083. [Link]

Dong, D., P. Fang, Y. Bock, M. K. Cheng, and S. Miyazaki, 2002: Anatomy of apparent seasonal variations from GPS-derived site position time series. J. Geophys. Res., 107, doi: 10.1029/2001jb000573. [Link]

Fleischer, R. L., 1981: Dislocation model for radon response to distant earthquakes. Geophys. Res. Lett., 8, 477-480, doi: 10.1029/g1008i005p00477. [Link]

Fu, C.-C., T. F. Yang, V. Walia, T.-K. Liu, S.-J. Lin, C.H. Chen, and C.-S. Hou, 2009: Variations of soil-gas composition around the active Chihshang Fault in a plate suture zone, eastern Taiwan. Radiat. Meas., 44, 940-944, doi: 10.1016/j.radmeas.2009.10.095. [Link]

Hartmann, J. and J. K. Levy, 2005: Hydrogeological and Gasgeochemical Earthquake Precursors? A Review for Application. Nat. Hazards, 34, 279-304, doi: 10.1007/ s1 1069-004-2072-2. [Link]

Juang, W.-S., 1993: Diversity and origin of quaternary basaltic magma series in northern Taiwan. Bull. National Museum of Natural Science, 4, 125-165.

Komori, S., T. Kagiyama, M. Utsugi, H. Inoue, and I. Azuhata, 2013: Two-dimensional resistivity structure of Unzen Volcano by AMT and MT surveys. Earth Planets Space, 65, 759-766, doi: 10.5047/eps.2012.10.005. [Link]

Konstantinou, K. I., C. H. Lin, and W. T. Liang, 2007: Seismicity characteristics of a potentially active Quaternary volcano: The Tatun Volcano Group, northern Taiwan. J. Volcanol. Geotherm. Res., 160, 300-318, doi: 10.1016/j.jvolgeores.2006.09.009. [Link]

Konstantinou, K. I., C. H. Lin, W. T. Liang, and Y. C. Chan, 2009: Seismogenic stress field beneath the Tatun Volcano Group, northern Taiwan. J. Volcanol. Geotherm. Res., 187, 261-271, doi: 10.1016/j. jvolgeores.2009.09.011. [Link]

Kumar, A., S. Singh, S. Mahajan, B. S. Bajwa, R. Kalia, and S. Dhar, 2009: Earthquake precursory studies in Kangra valley of North West Himalayas, India, with special emphasis on radon emission. Appl. Radiat. Isot., 67, 1904-1911, doi: 10.1016/j.apradiso.2009.05.016. [Link]

Kumar, A., V. Walia, T. F. Yang, H.-H. Chang, S.-J. Lin, K. P. Eappen, and B. R. Arora, 2013: Radon-thoron monitoring in Tatun volcanic areas of northern Taiwan using LR-115 alpha track detector technique: Pre-calibration and installation. Acta Geophys., 61, 958-976, doi: 10.2478/s11600-013-0120-6. [Link]

Kumar, A., V. Walia, B. R. Arora, T. F. Yang, S. J. Lin, C. C. Fu, C. H. Chen, and K. L. Wen, 2015: Identifications and removal of diurnal and semidiurnal variations in radon time series data of Hsinhua monitoring station in SW Taiwan using singular spectrum analysis. Nat. Hazards, 79, 317-330, doi: 10.1007/s11069-015-18441. [Link]

Lee, H. F., T. F. Yang, T. F. Lan, S. R. Song, and S. Tsao, 2005: Fumarolic gas composition of the Tatun Volcano Group, northern Taiwan. Terr. Atmos. Ocean. Sci., 16, 843-864, doi: 10.3319/TAO.2005.16.4.843(GIG). [Link]

Lin, C. H., 2016: Evidence for a magma reservoir beneath the Taipei metropolis of Taiwan from both S-wave shadows and P-wave delays. Sci.Rep., 6, doi: 10.1038/ srep39500. [Link]

Lin, C. H., K. I. Konstantinou, H. C. Pu, C. C. Hsu, Y. M. Lin, and S. Y. Y. Huang, 2005a: Preliminary results from seismic monitoring at the Tatun volcanic area of northern Taiwan. Terr. Atmos. Ocean. Sci., 16, 563577, doi: 10.3319/TAO.2005.16.3.563(T). [Link]

Lin, C. H., K. I. Konstantinou, W. T. Liang, H. C. Pu, Y. M. Lin, S. H. You, and Y. P. Huang, 2005b: Preliminary analysis of volcanoseismic signals recorded at the Tatun Volcano Group, northern Taiwan. Geophys. Res. Lett., 32, L10313, doi: 10.1029/2005GL022861. [Link]

Lin, C. H., T. F. Yang, C. S. Chen, and S. T. John, 2011: Volcanic Monitoring at the Tatun Volcano Group in the Yangmingshan National Park, 57 pp. (in Chinese)

Liu, C. M., S. R. Song, Y. L. Chen, and S. Tsao, 2011: Characteristics and origins of hot springs in the Tatun Volcano Group in northern Taiwan. Terr. Atmos. Ocean. Sci., 22, 475-489, doi: 10.3319/TAO.2011.05.25.01(TT). [Link]

Martinelli, G. and A. Dadomo, 2017: Factors constraining the geographic distribution of earthquake geochemical and fluid-related precursors. Chem. Geol., 469, 176184, doi: 10.1016/j.chemgeo.2017.01.006. [Link]

Monnin, M. M. and J. L. Seidel, 1997: Radon and Volcanic Surveillance. In: Durrani, S. A. and R. Ilic (Eds.), 
Radon Measurements by Etched Track Detectors: Applications in Radiation Protection, Earth Sciences and the Environment, World Scientific, 301-318, doi: 10.1142/9789812830197_0016. [Link]

Moreno, V., J. Bach, C. Baixeras, and L. Font, 2009: Characterization of blowholes as radon and thoron sources in the volcanic region of La Garrotxa, Spain. Radiat. Meas., 44, 929-933, doi: 10.1016/j.radmeas.2009.10.008. [Link]

Mouthereau, F., C. Fillon, and K. F. Ma, 2009: Distribution of strain rates in the Taiwan orogenic wedge. Earth Planet. Sci. Lett., 284, 361-385, doi: 10.1016/j. eps1.2009.05.005. [Link]

Murase, M., C.-H. Lin, F. Kimata, H. Mori, and H.-C. $\mathrm{Pu}$, 2014: Volcano-hydrothermal activity detected by precise levelling surveys at the Tatun volcano group in Northern Taiwan during 2006-2013. J. Volcanol. Geotherm. Res., 286, 30-40, doi: 10.1016/j. jvolgeores.2014.09.001. [Link]

Ohba, T., T. Sawa, N. Taira, T. F. Yang, H. F. Lee, T. F. Lan, M. Ohwada, N. Morikawa, and K. Kazahaya, 2010: Magmatic fluids of Tatun volcanic group, Taiwan. Appl. Geochem., 25, 513-523, doi: 10.1016/j.apgeochem.2010.01.009. [Link]

Ohsawa, S., H. F. Lee, B. Liang, S. Komori, C. H. Chen, and T. Kagiyama, 2013: Geochemical characteristics and origins of acid hot spring waters in Tatun Volcanic Group, Taiwan. J. Hot Spring Sci., 62, 282-293. (in Japanese)

Planinić, J., V. Radolić, and B. Vuković, 2004: Radon as an earthquake precursor. Nuclear Instruments and Methods in Physics Research A, 530, 568-574, doi: 10.1016/j.nima.2004.04.209. [Link]

Segovia, N., M. A. Armienta, C. Valdes, M. Mena, J. L. Seidel, M. Monnin, P. Peña, M. B. E. Lopez, and A. V. Reyes, 2003: Volcanic monitoring for radon and chemical species in the soil and in spring water samples. Radiat. Meas., 36, 379-383, doi: 10.1016/s13504487(03)00155-0. [Link]

Shyu, J. B. H., K. Sieh, Y. G. Chen, and C. S. Liu, 2005: Neotectonic architecture of Taiwan and its implications for future large earthquakes. J. Geophys. Res., 110, B08402, doi: 10.1029/2004jb003251. [Link]

Singh, M., M. Kumar, R. K. Jain, and R. P. Chatrath, 1999: Radon in ground water related to seismic events. Radiat. Meas., 30, 465-469, doi: 10.1016/s13504487(99)00049-9. [Link]

Tsao, S., 1994: K-Ar age determination of volcanic rocks from the Tatun Volcano Group. Bull. Cent. Geol. Surv., 9, 137-154. (in Chinese)

Virk, H. S., 1996: A critique of empirical scaling relationship between earthquake magnitude, epicentral distance and precursor time for interpretation of radon data. J. Earthq. Pred. Res., 5, 574-583.
Viveiros, F., T. Ferreira, C. Silva, And J. Gaspar, 2009: Meteorological factors controlling soil gases and indoor $\mathrm{CO} 2$ concentration: A permanent risk in degassing areas. Sci. Total Environ., 407, 1362-1372, doi: 10.1016/j.scitotenv.2008.10.009. [Link]

Walia, V., H. S. Virk, B. S. Bajwa, and N. Sharma, 2003: Relationships between radon anomalies and seismic parameters in N-W Himalaya, India. Radiat. Meas., 36, 393-396, doi: 10.1016/s1350-4487(03)00158-6. [Link]

Walia, V., H. S. Virk, T. F. Yang, S. Mahajan, M. Walia, and B. S. Bajwa, 2005: Earthquake prediction studies using radon as a precursor in N-W Himalayas, India: A case study. Terr. Atmos. Ocean. Sci., 16, 775-804, doi: 10.3319/TAO.2005.16.4.775(GIG). [Link]

Walia, V., T. F. Yang, W.-L. Hong, S.-J. Lin, C.-C. Fu, K.L. Wen, and C.-H. Chen, 2009: Geochemical variation of soil-gas composition for fault trace and earthquake precursory studies along the Hsincheng Fault in NW Taiwan. Appl. Radiat. Isot., 67, 1855-1863, doi: 10.1016/j.apradiso.2009.07.004. [Link]

Walia, V., T. F. Yang, S. J. Lin, A. Kumar, C. C. Fu, J. M. Chiu, H. H. Chang, K. L. Wen, and C. H. Chen, 2013: Temporal variation of soil gas compositions for earthquake surveillance in Taiwan. Radiat. Meas., 50, 154159, doi: 10.1016/j.radmeas.2012.11.007. [Link]

Wang, W.-H. and C.-H. Chen, 1990: The volcanology and fission track age dating of pyroclastic deposits in Tatun Volcano Group, northern Taiwan. Acta Geol. Taiwan., 28, 1-30.

Witt, M. L. I., T. P. Fischer, D. M. Pyle, T. F. Yang, and G. F. Zellmer, 2008: Fumarole compositions and mercury emissions from the Tatun Volcanic Field, Taiwan: Results from multi-component gas analyser, portable mercury spectrometer and direct sampling techniques. J. Volcanol. Geotherm. Res., 178, 636-643, doi: 10.1016/j.jvolgeores.2008.06.035. [Link]

Yang, T. F, Y. Sano, and S. R. Song, 1999: ${ }^{3} \mathrm{He} /{ }^{4} \mathrm{He}$ ratios of fumaroles and bubbling gases of hot springs in Tatun Volcano Group, North Taiwan. Il Nuovo Cimento $C$, 22, 281-286.

Yang, T. F., C.-H. Chen, R.-L. Tien, S. R. Song, and T. K. Liu, 2003: Remnant magmatic activity in the Coastal Range of East Taiwan after arc-continent collision: fission-track data and ${ }^{3} \mathrm{He} /{ }^{4} \mathrm{He}$ ratio evidence. Radiat. Meas., 36, 343-349, doi: 10.1016/S13504487(03)00149-5. [Link]

Yang, T. F., T. F. Lan, H. F. Lee, C. C. Fu, P. C. Chuang, C. H. Lo, C. H. Chen, C. A. Chen, and C. S. Lee, 2005a: Gas compositions and helium isotopic ratios of fluid samples around Kueishantao, NE offshore Taiwan and its tectonic implications. Geochem. J., 39, 469-480, doi: 10.2343/geochemj.39.469. [Link]

Yang, T. F., V. Walia, L. L. Chyi, C. C. Fu, C. H. Chen, 
T. K. Liu, S. R. Song, C. Y. Lee, and M. Lee, 2005b: Variations of soil radon and thoron concentrations in a fault zone and prospective earthquakes in SW Taiwan. Radiat. Meas., 40, 496-502, doi: 10.1016/j.rad- meas 2005.05.017. [Link]

Yu, S. B., H. Y. Chen, and L. C. Kuo, 1997: Velocity field of GPS stations in the Taiwan area. Tectonophysics, 274, 41-59, doi: 10.1016/s0040-1951(96)00297-1. [Link] 